\title{
Disease Burden and Healthcare Utilization Among Patients with Chronic Obstructive Pulmonary Disease (COPD) in England
}

\author{
Leah B Sansbury', David A Lipson $\mathbb{D}^{2,3}$, Chanchal Bains ${ }^{4}$, Glenn A Anley ${ }^{5}$, Kieran J Rothnie ${ }^{4}$, \\ Afisi S Ismaila $\mathbb{D D}^{6,7}$
}

'Value Evidence and Outcomes, Epidemiology, R\&D Global Medical, GlaxoSmithKline, Research Triangle Park, NC, USA; ${ }^{2}$ Respiratory Clinical Sciences, GlaxoSmithKline, Collegeville, PA, USA; ${ }^{3}$ Perelman School of Medicine, University of Pennsylvania, Philadelphia, PA, USA; ${ }^{4}$ Value Evidence and Outcomes, R\&D Global Medical, GlaxoSmithKline, Uxbridge, UK; ${ }^{5}$ UK Health Outcomes, GlaxoSmithKline, Uxbridge, UK; ${ }^{6}$ Value Evidence and Outcomes, GlaxoSmithKline, Collegeville, PA, USA; ${ }^{7}$ Department of Health Research Methods, Evidence and Impact, McMaster University, Hamilton, ON, Canada

Correspondence: Afisi S Ismaila, Value Evidence and Outcomes, GlaxoSmithKline, I250 South Collegeville Road, Collegeville, PA, I9426-0989, USA, Tel + I 919315 8229, Email afisi.s.ismaila@gsk.com

Purpose: Clinical guidelines for COPD management suggest pharmacologic treatment algorithms based on symptoms and exacerbation history. As previous research has suggested that prescribing patterns are not always aligned with these recommendations, this study investigated the burden of disease in patients with COPD receiving, and persisting on, new inhaled maintenance therapy.

Patients and Methods: This was a retrospective observational study using two linked electronic databases containing health records of patients in England. Patients aged $\geq 35$ years with a confirmed diagnosis of COPD, and who initiated a new inhaled respiratory pharmacologic maintenance regimen between January 1, 2014 and December 31, 2016 (index date) were eligible for inclusion. New treatments could be long-acting muscarinic antagonist (LAMA) or long-acting $\beta_{2}$-agonist (LABA) monotherapy, inhaled corticosteroid (ICS)/LABA or LAMA/LABA dual therapy, or a multiple-inhaler triple therapy (MITT; LAMA/LABA/ICS). Patients were required to have 12 months of available medical history prior to, and after, the index date.

Results: In total, 25,350 eligible patients were identified, of these 8282 (mean age: 70.9 years; $51.5 \%$ male) persisted with their newly prescribed inhaled therapy for $\geq 12$ months and were included in the analysis. In the 12 months prior to index, $54 \%$ of patients had moderate or severe dyspnea (Medical Research Council score $\geq 3$ ). The most common therapy initiated at index was MITT (42\%), followed by ICS/LABA dual therapy (31.2\%). The proportion of patients with moderate or severe dyspnea in the post-index period ranged from $29.0 \%$ of patients receiving ICS to $64.2 \%$ of patients receiving MITT. In the post-index period, $48.1 \%$ of patients experienced $\geq 1$ exacerbation and $54.9 \%$ had $\geq 5$ general practitioner visits.

Conclusion: Many of the patients with COPD in our study continued to experience symptoms and exacerbations, despite persisting on the same treatment for $\geq 12$ months. This suggests that some patients may benefit from treatment modification in accordance with guideline recommendations.

Keywords: chronic obstructive pulmonary disease, exacerbations, healthcare utilization, maintenance therapy, general practice

\section{Introduction}

Chronic obstructive pulmonary disease (COPD) is a progressive, irreversible disorder characterized by airway inflammation and persistent airflow limitation. ${ }^{1}$ In the UK, COPD is estimated to affect $2.6 \%$ of the overall population, ${ }^{2}$ and accounted for approximately $5 \%$ of all deaths in $2012 .{ }^{3}$ Disease management can be complicated by comorbidities, which are experienced by many patients with COPD. ${ }^{4} \mathrm{COPD}$ symptoms and exacerbations lead to increased healthcare resource use and associated costs. Symptom burden and direct healthcare costs for patients with COPD in the UK have been previously estimated through a cross-sectional survey in Northern Ireland ${ }^{5}$ and among patients with COPD in the UK following the use of long-acting bronchodilator therapy, ${ }^{6}$ but not yet across all therapeutic classes of COPD. A potential 
insufficiency with currently available COPD treatments was previously identified, as almost half of patients who started long-acting bronchodilator therapy continued to experience dyspnea during the 24-month follow-up period. ${ }^{6}$

The Global Initiative for Chronic Obstructive Lung Disease (GOLD) report, and the National Institute for Health and Care Excellence (NICE) clinical guidelines suggest pharmacologic treatment algorithms for patients with COPD, based on symptom severity and exacerbation history. ${ }^{1,7}$ Recent GOLD reports, published from 2017 onwards, also include a classification system to comprehensively assess COPD disease severity. In this assessment, patients are categorized into one of four groups (GOLD groups A-D) based on an assessment of symptoms and risk of exacerbation., ${ }^{1,8}$

Recent GOLD reports also recommend initial maintenance therapies that are appropriate for patients in each GOLD group: ${ }^{1,8}$ GOLD group A: short- or long-acting bronchodilators; GOLD group B: long-acting inhaled bronchodilators, including long-acting muscarinic antagonist (LAMA) or long-acting $\beta_{2}$-agonist (LABA); GOLD group C: single longacting bronchodilator (LAMA); GOLD group D: single long-acting bronchodilator (LAMA), or LAMA plus LABA in patients with severe symptoms. LABA plus an inhaled corticosteroid (ICS) may be an appropriate initial treatment for patients in this group especially with blood eosinophil counts $\geq 300$ cells $/ \mu \mathrm{L}$, or those with a history of asthma. The GOLD guidelines recommend initiating dual therapy treatment (LAMA/LAMA or LABA/ICS) followed by triple therapy (LAMA/LABA/ICS) in patients who continue to experience exacerbations or have poorly controlled symptoms. Further escalation to add roflumilast or a macrolide can be considered in patients who continue to experience exacerbations on triple therapy. ${ }^{1}$

Prescribing behavior is not always closely aligned with these evidence-based recommendations and some patients with COPD remain sub-optimally treated, suggesting that the guidelines are not fully utilized. ${ }^{9}{ }^{10}$ Understanding patient and disease factors that may contribute to COPD maintenance therapy prescription patterns may inform improvements in healthcare delivery. It is also important to identify groups of patients who continue to experience exacerbations despite receiving maintenance therapies.

The objective of this study was to investigate the burden of disease in patients with COPD receiving, and persisting on, inhaled maintenance therapy, by assessing patient demographics and clinical characteristics, disease burden, exacerbation rate, and healthcare utilization after initiating a new inhaled maintenance therapy.

\section{Materials and Methods}

\section{Study Design}

This observational, retrospective, longitudinal cohort study analyzed primary care records from the UK Clinical Practice Research Database - GP OnLine Data (CPRD-GOLD). This database was linked to secondary care records from the Hospital Episode Statistics Admitted Patient Care (HES-APC) database, covering a subset of patients registered with participating practices in England.

We identified patients with COPD who initiated a new inhaled maintenance therapy regimen (including a stepping up or switching to a new regimen) between January 1, 2014 and December 31, 2016 (Figure 1). Patients who received

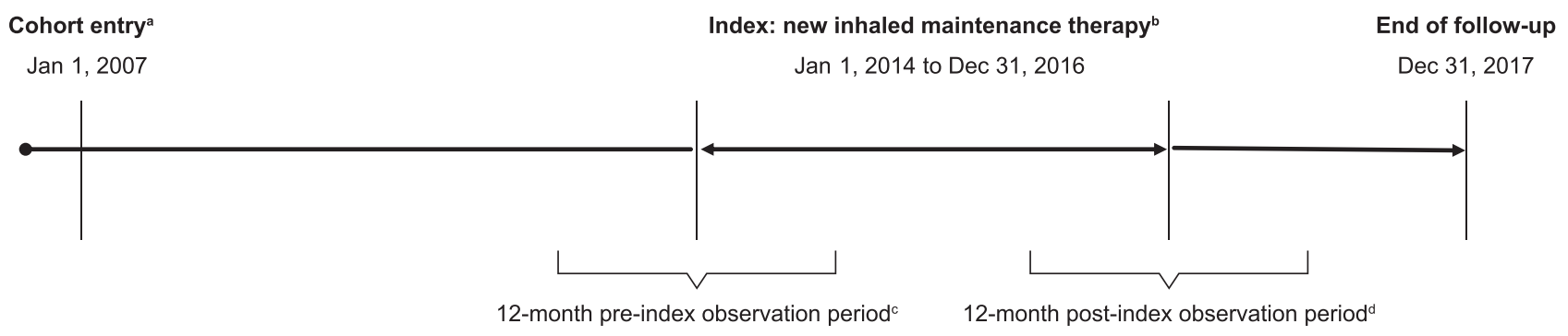

Figure I Study design.

Notes: ${ }^{a}$ COPD diagnosis between January I, 2007 and December 3I, 2016 and a spirometry record of FEV $/$ FVC $<0.7$ at any time. ${ }^{b} \mathrm{New}$ inhaled maintenance therapy (or class) prescribed between January I, 2014 and December 3I, 2016 (index date). Patients were assessed for persistence on their newly prescribed therapy (without switches, additions or step-up/down) for 12 months post-index. 'Patients had at least 12 months' history available in the database prior to the index date. ${ }^{d}$ Future outcomes of interest were ascertained from the database 12 months post-index, up to December 3I, 2017.

Abbreviations: $\mathrm{FEV}_{1}$, forced expiratory volume in I second; FVC, forced vital capacity. 
continuous prescriptions for the new maintenance therapy for $\geq 12$ months (without further prescription switches, additions, or step-ups/downs) were included in the analysis. The prescription initiation date (index date) was the date the new inhaled maintenance therapy was prescribed. If a patient persisted on $>1$ inhaled maintenance therapy during the observational period, the first newly prescribed inhaled treatment that persisted for $\geq 12$ months was selected (or the first new treatment prescription date, if more than one therapy was used for $\geq 12$ months).

\section{Study Population}

Eligible patients were required to be $\geq 35$ years old at COPD diagnosis ${ }^{7}$ and also have: a COPD diagnosis between January 1, 2007 and December 31, 2016; a record of forced expiratory volume in 1 second/forced vital capacity $\left(\mathrm{FEV}_{1} / \mathrm{FVC}\right)<0.7$ at any time in the patient's medical history; HES-APC-linked records; prescription of a new inhaled COPD maintenance therapy (LAMA, LABA, LAMA/LABA, LABA/ICS, or multiple-inhaler triple therapy [MITT] consisting of LAMA/LABA/ICS); no prior use of the newly prescribed inhaled maintenance therapy (including drugs of a similar class) in the 12 months prior to the index date; and at least 12 months of history in the CPRD-GOLD database prior to, and post, index. For the purposes of the current analysis, patients were also required to persist on their newly initiated therapy for $\geq 12$ months following the index date.

Patients were excluded if their medical history contained a condition that was incompatible with the diagnosis of COPD, including conditions related to lung or bronchial developmental anomalies, degenerative processes, pulmonary resection or other significant respiratory disorders, or lung malformations, other than COPD.

\section{COPD Maintenance Treatment}

The new inhaled maintenance therapy could be a monotherapy (LAMA or LABA), a dual therapy (ICS/LABA or LAMA/LABA), or a MITT (LAMA/LABA/ICS). Patients who persisted on the new inhaled maintenance therapy for $\geq 12$ months were included in the analysis. Persistent medication use was defined as continuous use of the specified therapy for at least 12 months with a gap of $\leq 90$ days from the last known prescription date for LAMA, LABA, ICS/LABA, LAMA/LABA, and $\leq 30$-day gap from the discontinuation of any component of MITT therapy. Persistent medication use did not permit the concurrent use of any additional treatments, with the exception of short-acting bronchodilators. Persistent use of MITT was estimated using an algorithm that calculated a duration for each prescription, based on the number of units (inhalations, puffs) prescribed in primary care and the number of units that the patient was expected to take each day (numeric daily dose). ${ }^{11}$

\section{Data Source}

Data were obtained from the CPRD-GOLD database, which contains anonymized, longitudinal medical records of patients registered with contributing primary care practices across the UK. Data were obtained from the database using Vision electronic health record software. HES is a data warehouse containing details of all inpatient episodes of care (including day cases), outpatient appointments, and Accident \& Emergency attendances at National Health Service (NHS) hospitals in England. Linkage of CPRD-GOLD data to HES was carried out by the Health and Social Care Information Centre.

\section{Data Analysis}

Patient demographics and clinical characteristics (including past COPD medication use) were described in the 12 months prior to the index date. Disease burden and healthcare utilization were evaluated in the 12 months prior to and after the index date using the following measures: Medical Research Council (MRC) dyspnea scale (grade 1-5); ${ }^{12}$ GOLD grade of airflow limitation (GOLD 1-4); GOLD 2017 COPD category (category A-D); ${ }^{8}$ number and severity of acute exacerbations of COPD; number of hospitalizations and primary-care consultations.

COPD exacerbations were identified from the CPRD-GOLD database and HES based on a validated algorithm. ${ }^{13}$ According to the algorithm, COPD exacerbations in primary care were defined as the presence of a record for one of the four following events: prescriptions for antibiotics and oral corticosteroids for a duration of 5 to 14 days each; presence of respiratory symptoms (indicated by a medical code suggesting an increase in two or more of the following symptoms: 
dyspnea, cough, or sputum volume and/or purulence recorded on the same date) and a prescription for antibiotics and/or oral corticosteroids on the same day; lower respiratory tract infection medical code; or an exacerbation-specific medical code. ${ }^{13}$

Linked HES-ACP data were used to identify exacerbations that were associated with a hospitalization, using International Classification of Diseases (ICD)-10 codes. Exacerbations resulting in hospitalization (ie, recorded in HES-ACP and/or CPRD-GOLD) were classified as severe, and exacerbations managed only in primary care (ie, only recorded in CPRD-GOLD) were defined as moderate. A maximum of one hospitalization or primary-care encounter was recorded per day to avoid multiple counting of the same events.

\section{Results}

\section{Patient Baseline Demographics and Clinical Characteristics Prior to Index Date}

We identified 25,350 patients with COPD who initiated a new therapy during the study period. Among these patients, the therapy type initiated at index was as follows: ICS only, 10.2\%; LAMA only, 21.9\%; LABA only, 3.3\%; ICS and LABA, 32.5\%; ICS and LAMA, 1.4\%; LABA and LAMA, 1.7\%; and MITT, $28.9 \%$. Of the total population, 8282 (51.5\% male, mean age 70.9 years) persisted with their newly prescribed maintenance therapy for $\geq 12$ months without any changes and were eligible for inclusion in the analysis presented here.

Baseline characteristics are shown in Table 1. Most patients were either ex-smokers (57.1\%) or current smokers (36.7\%), and $61.5 \%$ of patients were overweight or obese. Prior to initiating the index maintenance therapy, approximately two-thirds $(63.4 \%)$ of patients had moderate or severe dyspnea, indicated by MRC score $\geq 3$. During the 12 months prior to index, $26.5 \%$ of patients were categorized as GOLD grade A (low exacerbation risk, low symptom burden), 49.9\% were GOLD grade B (low exacerbation risk, high symptom burden), 4.7\% were GOLD grade $\mathrm{C}$ (high exacerbation risk, low symptom burden), and 19.0\% were GOLD grade D (high exacerbation risk, high symptom burden). In total, $94.8 \%$ of patients with COPD had used a maintenance therapy in the 12 months prior to the treatment initiated at index; the most frequently prescribed past therapies were short-acting bronchodilators $(86.6 \%$ of patients), ICS/LABA (45.6\%), and MITT (40.7\%).

\section{COPD Maintenance Therapy}

The most common therapy initiated was MITT with ICS, LAMA, and LABA (42.0\%), followed by ICS/LABA (31.3\%), LAMA only (15.7\%), ICS only (6.7\%), LABA only (2.0\%), LAMA/LABA (1.3\%), and ICS/LAMA (1.1\%) (Figure 2). In the 12-month observation period, and among patients with available MRC score data, the proportion of patients with moderate or severe dyspnea (MRC score $\geq 3$ ) ranged from $23.4 \%$ in patients receiving ICS, to $69.3 \%$ in patients receiving MITT (Table 2). Of the patients with available MRC score data, $40.9 \%$ of patients receiving ICS/LABA, and $46.7 \%$ of patients receiving LAMA/LABA experienced moderate or severe dyspnea. Among patients receiving MITT, and with available GOLD group data, 41.6\% were categorized as GOLD group B (low exacerbation risk, high symptom burden) and $35.4 \%$ as GOLD group D (high exacerbation risk, high symptom burden) in the 12-month observation period (Table 2).

\section{Incidence of Exacerbations}

During the 12 months prior to index, $45.4 \%$ of patients experienced an exacerbation, with $6.0 \%$ of patients experiencing a severe exacerbation (Table 1). Among patients who initiated MITT, 58.8\% experienced an exacerbation during the 12-month pre-index period, with $9.5 \%$ experiencing a severe exacerbation. During the 12 -month post-index period, almost half of all patients (48.1\%) experienced $\geq 1$ exacerbation (Table 3 ). In total, $27.9 \%$ of patients had $\geq 2$ moderate or $\geq 1$ severe exacerbation. Severe COPD exacerbations were experienced by $7.9 \%$ of patients. Of the patients who were receiving MITT, 61.7\% experienced a moderate or severe exacerbation during the 12 months of observation (Table 3) and $12.7 \%$ experienced a severe exacerbation.

\section{Healthcare Utilization}

Most patients (54.9\%) had $\geq 5$ all-cause general practitioner (GP) visits during the 12-month observation period, irrespective of their prescribed therapy (Figure 3). The mean number of nurse and physician visits during the 12-month observation period 
Table I Patient Demographics and Clinical Characteristics, Overall and by Maintenance Therapy Initiated

\begin{tabular}{|c|c|c|c|c|c|c|c|c|}
\hline & Overall & ICS & LAMA & LABA & ICS/LABA & ICS/LAMA & LAMA/LABA & MITT \\
\hline Total, n (\%) & $8282(100.0)$ & $558(6.7)$ & $1299(15.7)$ & $165(2.0)$ & $2588(31.3)$ & $92(1.1)$ & $105(1.3)$ & $3475(42.0)$ \\
\hline Male, n (\%) & $4267(51.5)$ & $257(46.1)$ & $722(55.6)$ & 77 (46.7) & $1300(50.2)$ & $42(45.7)$ & $55(52.4)$ & $1814(52.2)$ \\
\hline Age, mean (SD) years & $70.93(10.2)$ & $71.98(11.2)$ & $71.37(9.6)$ & $70.79(9.8)$ & $70.62(11.0)$ & $73.64(9.7)$ & $70.60(10.2)$ & $70.77(9.6)$ \\
\hline \multicolumn{9}{|l|}{ Smoking status, n (\%) } \\
\hline Ex-smoker & $4727(57.1)$ & $315(56.6)$ & $684(52.7)$ & $92(56.1)$ & $1415(54.7)$ & $55(59.8)$ & $56(53.3)$ & $2110(60.8)$ \\
\hline Never smoked & $512(6.2)$ & $58(10.4)$ & $42(3.2)$ & $3(1.8)$ & $284(11.0)$ & $5(5.4)$ & $3(2.9)$ & $117(3.4)$ \\
\hline Current smoker & $3036(36.7)$ & $184(33.0)$ & $573(44.1)$ & $69(42.1)$ & $886(34.3)$ & $32(34.8)$ & $46(43.8)$ & 1246 \\
\hline \multicolumn{9}{|l|}{ BMI, n (\%) } \\
\hline Underweight $(<18.5)$ & $376(4.7)$ & $26(4.8)$ & $55(4.3)$ & $5(3.2)$ & $80(3.2)$ & $7(7.7)$ & $2(2.0)$ & $201(6.0)$ \\
\hline Normal $(18.5$ to $<25.0)$ & $2555(31.8)$ & $175(32.4)$ & $403(31.8)$ & $38(24.2)$ & $784(3 \mid .4)$ & $25(27.5)$ & $24(23.8)$ & $1106(32.8)$ \\
\hline Overweight $(25.0$ to $<30.0)$ & $2723(33.9)$ & $179(33.2)$ & $463(36.5)$ & $62(39.5)$ & $880(35.3)$ & $38(41.8)$ & $43(42.6)$ & $1058(31.3)$ \\
\hline Obese $(\geq 30.0)$ & $2374(29.6)$ & $160(29.6)$ & $347(27.4)$ & $52(33.1)$ & $751(30.1)$ & $21(23.1)$ & $32(31.7)$ & $1011(30.0)$ \\
\hline Moderate or severe dyspnea ${ }^{a, b, c}, n$ (\%) & $4474(63.4)$ & $109(39.4)$ & $506(45.6)$ & $70(48.6)$ & $1098(52.4)$ & $48(58.5)$ & $64(66.7)$ & $2579(79.4)$ \\
\hline \multicolumn{9}{|l|}{ GOLD 2017 grade of airflow limitation ${ }^{\mathrm{a}, \mathrm{c}}, \mathrm{n}$ (\%) } \\
\hline GOLD I & $304(6.5)$ & $23(9.5)$ & $56(6.7)$ & $8(6.6)$ & $91(7.0)$ & $5(8.8)$ & $5(7.8)$ & $116(5.6)$ \\
\hline GOLD 2 & $3090(65.8)$ & $191(78.9)$ & $631(74.9)$ & $98(80.3)$ & $936(71.7)$ & $46(80.7)$ & $44(68.8)$ & II $44(55.4)$ \\
\hline GOLD 3 & $|23|(26.2)$ & $28(11.6)$ & $152(18.1)$ & $16(13.1)$ & $272(20.8)$ & $6(10.5)$ & $15(23.4)$ & $742(35.9)$ \\
\hline GOLD 4 & $73(1.6)$ & 0 & $3(0.4)$ & 0 & $7(0.5)$ & 0 & 0 & $63(3.1)$ \\
\hline \multicolumn{9}{|l|}{ GOLD 2017 group $^{\mathrm{a}}$, n (\%) } \\
\hline GOLD A & $2192(26.5)$ & $152(27.2)$ & $538(4 \mid .4)$ & $68(4 I .2)$ & $870(33.6)$ & $29(31.5)$ & $28(26.7)$ & $507(14.6)$ \\
\hline GOLD B & $4|3|(49.9)$ & $343(61.5)$ & $608(46.81)$ & $78(47.3)$ & $1255(48.5)$ & $55(59.8)$ & $68(64.8)$ & $1724(49.6)$ \\
\hline GOLD C & $388(4.7)$ & $16(2.9)$ & $65(5.0)$ & $6(3.6)$ & $129(5.0)$ & $5(5.4)$ & $4(3.8)$ & $163(4.7)$ \\
\hline GOLD D & $|57|(19.0)$ & $47(8.4)$ & $88(6.8)$ & $13(7.9)$ & $334(12.9)$ & $3(3.3)$ & $5(4.8)$ & $1081(31.1)$ \\
\hline \multicolumn{9}{|l|}{ History of comorbidity, n (\%) } \\
\hline Anxiety & $1376(16.6)$ & $96(17.2)$ & $212(16.3)$ & $32(19.4)$ & $447(17.3)$ & $15(16.3)$ & $12(11.4)$ & $562(16.2)$ \\
\hline Depression & $1166(14.1)$ & $60(10.8)$ & $178(13.7)$ & $27(16.4)$ & $357(13.8)$ & $14(15.2)$ & $16(15.2)$ & $514(14.8)$ \\
\hline Gastroesophageal reflux disease & $1377(16.6)$ & $94(16.9)$ & $20 I(15.5)$ & $26(15.8)$ & $419(16.2)$ & $17(18.5)$ & $18(17.1)$ & $602(17.3)$ \\
\hline Herpes zoster & $1047(12.6)$ & $63(11.3)$ & $174(13.4)$ & $22(13.3)$ & $326(12.6)$ & II (12.0) & II (10.5) & $440(12.7)$ \\
\hline Heart failure & $485(5.9)$ & $25(4.5)$ & $76(5.9)$ & $8(4.9)$ & $124(4.8)$ & $5(5.4)$ & $4(3.8)$ & $243(7.0)$ \\
\hline Myocardial infarction & $562(6.8)$ & $49(8.8)$ & $109(8.4)$ & $15(9.1)$ & $153(5.9)$ & $10(10.9)$ & $\mathrm{I}(\mathrm{I} .0)$ & $225(6.5)$ \\
\hline Stroke & $350(4.2)$ & $26(4.7)$ & $56(4.3)$ & $5(3.0)$ & $110(4.3)$ & 0 & $4(3.8)$ & $149(4.3)$ \\
\hline Asthma & $2010(24.3)$ & $219(39.3)$ & $77(5.9)$ & $17(10.3)$ & $936(36.2)$ & $21(22.8)$ & $6(5.7)$ & $734(21.1)$ \\
\hline \multicolumn{9}{|l|}{ Exacerbation history, n (\%) } \\
\hline All & $3761(45.4)$ & $155(27.8)$ & $424(32.6)$ & $62(37.6)$ & $1023(39.5)$ & $27(29.3)$ & $27(25.7)$ & $2043(58.8)$ \\
\hline Moderate & $3543(42.8)$ & $145(26.0)$ & $391(30.1)$ & $61(37.0)$ & $974(37.6)$ & $27(29.4)$ & $26(24.8)$ & $1919(55.2)$ \\
\hline Severe & $495(6.0)$ & $13(2.3)$ & $50(3.9)$ & $2(1.2)$ & $97(3.8)$ & 0 & $2(1.9)$ & $331(9.5)$ \\
\hline
\end{tabular}




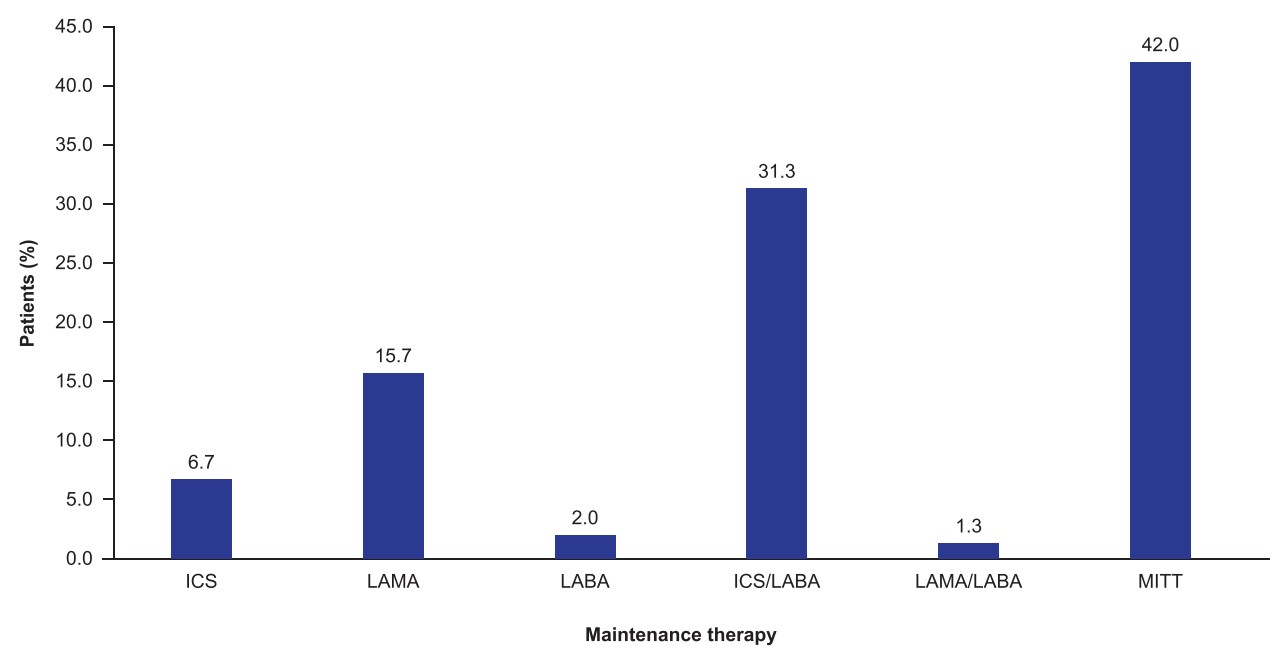

Figure 2 Maintenance therapies prescribed at index.

Notes: Patients treated with ICS/LAMA ( $\mathrm{n}=92 ; 1.1 \%)$ are not included in this figure.

Abbreviations: ICS, inhaled corticosteroid; LABA, long-acting $\beta_{2}$-agonist; LAMA, long-acting muscarinic antagonist; MITT, multiple-inhaler triple therapy.

was 4.1 and 6.7, respectively. In the 12-month observation period, a large majority of patients $(94.4 \%)$ did not have any unplanned hospital admissions for COPD and 5.4\% of patients had 1-2 unplanned admissions.

\section{Discussion}

This large observational study assessed patient demographics, clinical characteristics, disease burden, and healthcare utilization over 12 months in a typical population of patients with COPD who initiated, and persisted on, a new inhaled maintenance therapy in England. A large proportion of patients who were receiving monotherapy, dual therapies, or MITT continued to experience COPD symptoms and exacerbations, despite persisting with the same treatment for $\geq 12$ months. For example, among patients receiving ICS/LABA, $44 \%$ experienced $\geq 1$ moderate or severe exacerbation and $41 \%$ reported moderate/

Table 2 Disease Burden in the 12-Month Post-Index Observation Period

\begin{tabular}{|c|c|c|c|c|c|c|}
\hline & $\begin{array}{c}\text { Overall } \\
\text { n (\%) }\end{array}$ & $\begin{array}{c}\text { ICS } \\
\text { n (\%) }\end{array}$ & $\begin{array}{c}\text { LAMA } \\
\text { n (\%) }\end{array}$ & $\begin{array}{c}\text { ICS/LABA } \\
\text { n (\%) }\end{array}$ & $\begin{array}{c}\text { LAMA/LABA } \\
\text { n (\%) }\end{array}$ & $\begin{array}{l}\text { MITT } \\
\text { n (\%) }\end{array}$ \\
\hline Overall population & $8282(100)$ & $558(6.7)$ & $1299(15.7)$ & $2588(31.3)$ & $105(1.3)$ & $3475(42.0)$ \\
\hline $\begin{array}{l}\text { Moderate or severe } \\
\text { dyspnea }^{a, b, c} \\
\text { GOLD } 2017 \text { grade of }^{a, c} \\
\text { airflow limitation }^{a, c}\end{array}$ & $4372(52.8)$ & $|3|(23.4)$ & $626(48.2)$ & $1058(40.9)$ & $49(46.7)$ & $2407(69.3)$ \\
\hline GOLD I & $316(7.6)$ & $28(11.3)$ & $49(7.1)$ & $90(8.0)$ & $4(7.4)$ & $14 \mid(7.4)$ \\
\hline GOLD 2 & $2680(64.7)$ & $190(76.9)$ & $527(76.7)$ & $811(72.0)$ & $38(70.4)$ & $1002(52.9)$ \\
\hline GOLD 3 & $1050(25.3)$ & $27(10.9)$ & $106(15.4)$ & $217(19.3)$ & $12(22.2)$ & $670(35.4)$ \\
\hline GOLD 4 & $98(2.4)$ & $2(0.8)$ & $5(0.7)$ & $9(0.8)$ & 0 & $82(4.3)$ \\
\hline \multicolumn{7}{|l|}{ GOLD 2017 group $^{\mathrm{a}, \mathrm{d}}$} \\
\hline GOLD A & $2107(30.4)$ & $137(46.9)$ & $517(43.0)$ & $768(38.2)$ & $39(42.4)$ & $548(I 7.5)$ \\
\hline GOLD B & $2832(40.9)$ & III (38.0) & $522(43.4)$ & 778 (38.7) & $40(43.5)$ & $130 \mid(4 \mid .6)$ \\
\hline GOLD C & $452(6.5)$ & $24(8.2)$ & $59(4.9)$ & $182(9.1)$ & $4(4.3)$ & $169(5.4)$ \\
\hline GOLD D & $1540(22.2)$ & $20(6.8)$ & $104(8.7)$ & $281(14.0)$ & $9(9.8)$ & $1106(35.4)$ \\
\hline
\end{tabular}

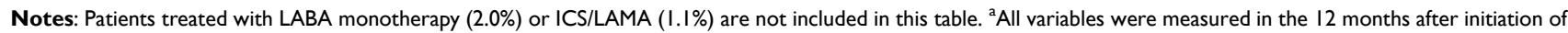

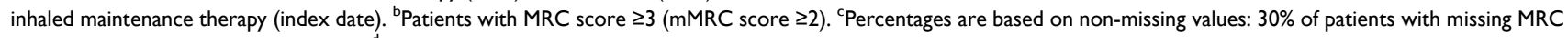
and $47 \%$ with missing spirometry data. ${ }^{d}$ Defined by 12 -month exacerbation history after index date with MRC closest to index date.

Abbreviations: COPD, chronic obstructive pulmonary disease; GOLD, Global Initiative for Chronic Obstructive Lung Disease; ICS, inhaled corticosteroid; LABA, longacting $\beta_{2}$-agonist; LAMA, long-acting muscarinic antagonist; MITT, multiple-inhaler triple therapy; (m)MRC, (modified) Medical Research Council. 
Table 3 Exacerbation Events in the 12-Month Post-Index Observation Period

\begin{tabular}{|c|c|c|c|c|c|c|}
\hline & $\begin{array}{l}\text { Overall } \\
\text { n (\%) }\end{array}$ & $\begin{array}{c}\text { ICS } \\
\text { n (\%) }\end{array}$ & $\begin{array}{l}\text { LAMA } \\
\text { n (\%) }\end{array}$ & $\begin{array}{c}\text { ICS/LABA } \\
\text { n (\%) }\end{array}$ & $\begin{array}{c}\text { LAMA/LABA } \\
\text { n (\%) }\end{array}$ & $\begin{array}{l}\text { MITT } \\
\text { n (\%) }\end{array}$ \\
\hline $\begin{array}{l}\text { Overall population } \\
\text { Exacerbation events } \\
\text { (moderate or } \\
\text { severe) }^{\text {a }}\end{array}$ & $8282(100)$ & $558(6.7)$ & $1299(15.7)$ & $2588(31.3)$ & $105(1.3)$ & $3475(42.0)$ \\
\hline 0 & 4299 (51.9) & $388(69.5)$ & $888(68.4)$ & $1460(56.4)$ & $65(61.9)$ & $1332(38.3)$ \\
\hline I & $1839(22.2)$ & $109(19.5)$ & $256(19.7)$ & $594(23.0)$ & $28(26.7)$ & 796 (22.9) \\
\hline$\geq 2$ & $2144(25.9)$ & $61(10.9)$ & 155 (II.9) & $534(20.6)$ & $12(11.4)$ & $1347(38.8)$ \\
\hline Any exacerbation & $3983(48.1)$ & $170(30.5)$ & $4 I I(31.6)$ & $1128(43.6)$ & $40(38.1)$ & $2143(61.7)$ \\
\hline $\begin{array}{l}\text { Rate of moderate or } \\
\text { severe exacerbation } \\
(95 \% \mathrm{Cl})\end{array}$ & $\begin{array}{c}1.01 \\
(0.99,1.03)\end{array}$ & $\begin{array}{c}0.61 \\
(0.57,0.66)\end{array}$ & $\begin{array}{c}0.80 \\
(0.77,0.84)\end{array}$ & $\begin{array}{c}0.94 \\
(0.91,0.97)\end{array}$ & $\begin{array}{c}0.80 \\
(0.69,0.93)\end{array}$ & $\begin{array}{c}\mathrm{I} .44 \\
(\mathrm{I} .40,1.49)\end{array}$ \\
\hline $\begin{array}{l}\geq 2 \text { moderate or } \geq 1 \\
\text { severe exacerbation }\end{array}$ & $2313(27.9)$ & $66(11.8)$ & $174(13.4)$ & $579(22.4)$ & $14(13.3)$ & I437 (4I.4) \\
\hline Severe exacerbation ${ }^{b}$ & $652(7.9)$ & $16(2.9)$ & $44(3.4)$ & $|3|(5.1)$ & $4(3.8)$ & $442(12.7)$ \\
\hline $\begin{array}{l}\text { Rate of severe } \\
\text { exacerbation }(95 \% \\
\text { Cl) }\end{array}$ & $\begin{array}{c}0.12 \\
(0.11,0.12)\end{array}$ & $\begin{array}{c}0.05 \\
(0.04,0.06)\end{array}$ & $\begin{array}{c}0.09 \\
(0.08,0.10)\end{array}$ & $\begin{array}{c}0.10 \\
(0.09,0.11)\end{array}$ & $\begin{array}{c}0.09 \\
(0.06,0.13)\end{array}$ & $\begin{array}{c}0.18 \\
(0.17,0.20)\end{array}$ \\
\hline
\end{tabular}

Notes: a All variables were measured in the 12 months after initiation of inhaled maintenance therapy (index date). ${ }^{b}$ Severe exacerbation event is defined by an exacerbation resulting in hospitalization.

Abbreviations: $\mathrm{Cl}$, confidence interval; COPD, chronic obstructive pulmonary disease; ICS, inhaled corticosteroid; LABA, long-acting $\beta_{2}$-agonist; LAMA, long-acting muscarinic antagonist; MITT, multiple-inhaler triple therapy.

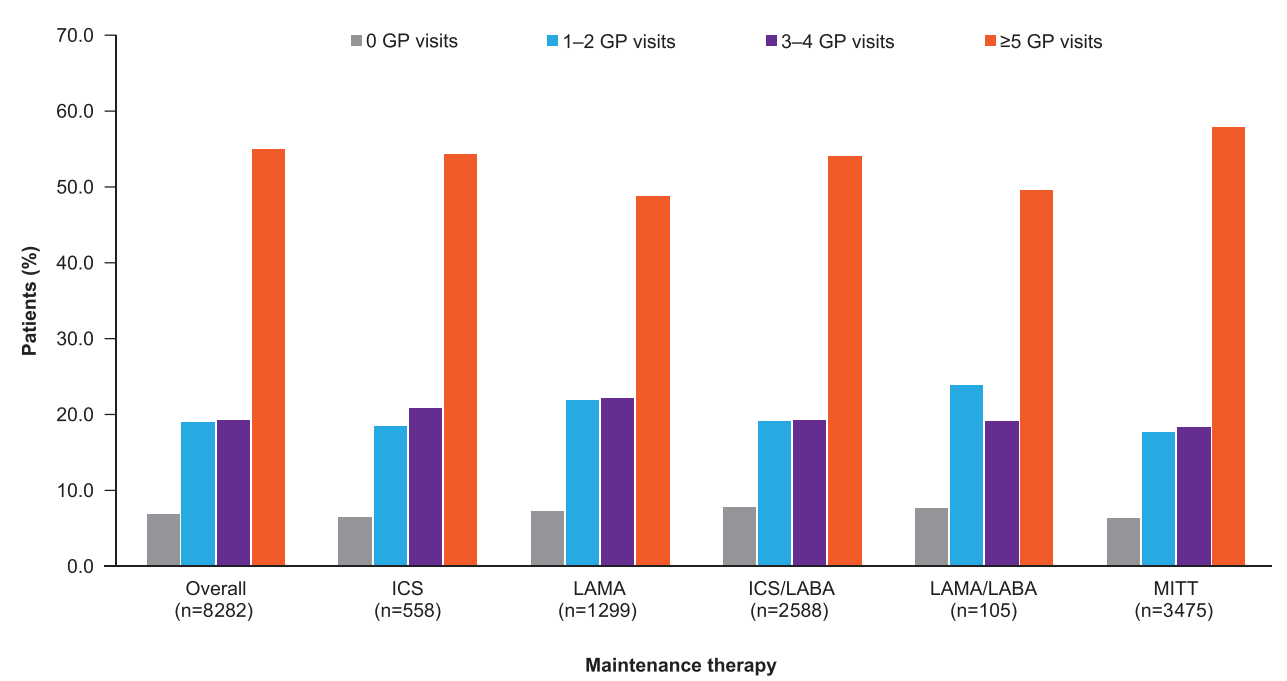

Figure 3 General practitioner visits in the 12-month post-index observation period.

Notes: Patients treated with LABA monotherapy $(n=165 ; 2.0 \%)$ and ICS/LAMA $(n=92 ; 1.1 \%)$ are not included in this figure. All variables were measured in the 12 months after initiation of inhaled maintenance therapy (index date). Percentages are based upon the number of patients ( $n$ ) in each maintenance therapy group.

Abbreviations: GP, general practitioner; ICS, inhaled corticosteroid; LABA, long-acting $\beta_{2}$-agonist; LAMA, long-acting muscarinic antagonist; MITT, multiple-inhaler triple therapy. 
severe dyspnea in the 12-month observation period. These results suggest that many patients with COPD who are receiving mono or dual bronchodilator therapy may be suitable for more intensive treatment or treatment optimization, to maximize bronchodilation and reduce the risk of future exacerbations. It is possible that these patients may have benefited from a modified treatment strategy, for example initiation of inhaled triple therapy. Previous studies have found that use of multiple inhalers is associated with a lack of treatment adherence or inhaler errors, which may be compounded if different devices are used, ${ }^{14-16}$ which may explain our findings. These findings also indicate that an unmet need may still exist for some patients with COPD who remain symptomatic despite receiving triple therapy. Additional therapies and disease management may be required to fully control symptoms among patients in this group who wish to further escalate treatment. For some patients, however, particularly those who are older or have many comorbidities, continued exacerbations and hospital admissions may not represent avoidable outcomes which are amenable to prevention by escalation of inhaled treatment. In addition to escalating treatment, other factors should be considered, such as inhalation technique, the suitability of the inhaler for the individual and adherence to earlier treatment steps. Pulmonary rehabilitation is also a well-supported intervention for symptomatic patients, ${ }^{17}$ which could be explored.

Nearly half $(48.1 \%)$ of the patients in our study experienced $\geq 1$ exacerbation in the 12 months after starting a new maintenance therapy. Patients who initiated MITT, and persisted for 12 months, were more likely to experience $\geq 1$ exacerbation, compared with patients prescribed other maintenance therapies. However, this may be explained by differences in COPD disease severity; patients starting MITT had higher disease burden in the preindex period (in terms of the GOLD grade of airflow limitation and GOLD COPD category) compared with patients starting other therapies.

Most patients had $\geq 5$ GP visits during the 12-month observation period, irrespective of the prescribed therapy. These results demonstrate a continued high demand on the healthcare system despite persistence with a prescribed maintenance therapy. A recent French observational study reported that among patients with COPD who persisted with a new therapy for 12 months, $61.2 \%$ experienced an exacerbation (compared with $48.1 \%$ in our analysis). ${ }^{18}$ Symptom burden and direct healthcare costs have also been previously assessed in UK patients who started long-acting bronchodilator therapy. Overall, $40-50 \%$ of patients continued to experience breathlessness during the 24-month follow-up period, including among treatment-adherent patients. ${ }^{6}$

Previous studies have demonstrated that long-term adherence to inhaled COPD therapy is associated with improvements in clinical outcomes and reduced healthcare utilization. ${ }^{19-22}$ For example, in the Towards a Revolution in COPD Health (TORCH) study, the impact of adherence to inhaled therapy on mortality and morbidity was assessed in $>8500$ patients with moderate to severe COPD. Good adherence to therapy (defined as $>80 \%$ of inhaled doses taken over 3 years) was associated with a reduced risk of death (hazard ratio [HR]: 0.40; 95\% confidence interval $[\mathrm{CI}]: 0.35,0.46 ; p<0.001$ ) and reduced hospital admissions due to exacerbations (rate ratio [RR]: $0.56 ; 95 \%$ CI: $0.48,0.65 ; p<0.001)$ compared with poor adherence $\left(\leq 80 \%\right.$ of inhaled doses taken) ${ }^{22}$

Previous studies have reported low levels of treatment adherence and persistence among patients with COPD in the $\mathrm{UK}^{23}$ and in other countries. ${ }^{24-26}$ Complex treatment regimens and the use of multiple inhalers are reported to have a negative effect on treatment adherence in patients with COPD. ${ }^{26}$ In 2017, the European Medicines Agency approved the first once-daily, single-inhaler triple therapy (SITT) consisting of fluticasone furoate/ umeclidinium/vilanterol (FF/UMEC/VI) as a long-term maintenance treatment for adult patients with moderate to severe COPD. ${ }^{27}$ Two SITTs requiring twice-daily dosing have also been approved in Europe: beclomethasone/ formoterol/glycopyrronium bromide was approved in $2017,{ }^{28}$ followed by budesonide/glycopyrronium bromide/ formoterol in $2020 .{ }^{29}$ The efficacy of SITT to provide COPD symptom control, reduce moderate/severe exacerbation rate, improve quality of life, and reduce all-cause mortality risk has been demonstrated in patients with moderate to very severe COPD. ${ }^{30-37}$ In particular, significantly more patients in the INTREPID trial who were treated with FF/UMEC/VI achieved health status improvement compared to those receiving non-ELLIPTA MITT. ${ }^{38}$ These improvements could be attributed to improved adherence with SITT, and a resultant lack of missed doses that is associated with the use of multiple inhalers. Patients with moderate to severe COPD who require triple therapy may therefore benefit from switching to SITT, which has the potential to improve both 
adherence and outcomes. ${ }^{38-40}$ Indeed, in a recent study carried out in the USA, patients with COPD initiating $\mathrm{FF} / \mathrm{UMEC} / \mathrm{VI}$ were found to have better adherence than those initiating MITT. ${ }^{14}$

A recent study using an economic model estimated that increased use of SITT in patients with moderate to severe COPD would be associated with improved adherence, decreased exacerbation and mortality rates, and healthcare cost savings. ${ }^{41}$ Future research investigating the suboptimal treatment of patients with COPD who experience persistent symptoms and exacerbations is needed to address the limitations faced by healthcare professionals aiming to optimize treatment according to current GOLD recommendations.

There are several strengths of this study that should be mentioned, including the large population size and longitudinal design; medical records from over 8000 patients with COPD were analyzed over the study observation period. The study used routinely captured primary care and hospital data from patients receiving treatment in a real-world setting, providing a representative sample of patients with diagnosed COPD in England. In addition, it has previously been demonstrated that the CPRD-GOLD database is broadly representative of the UK population with regards to age, gender, and sociodemographic status. ${ }^{42}$ A further strength of the study is that patient diagnosis of COPD was confirmed by $\mathrm{FEV}_{1} / \mathrm{FVC}$ data.

The study has a few limitations that should be mentioned. The CPRD-GOLD database only captures diseases diagnosed or recorded in the primary care setting in the UK, and therefore the generalizability of the findings may be limited outside of the UK. In addition, only patients from England were included in the analysis, as HES linkage was only available for patients residing in England. However, despite this limitation, HES linkage allows identification of severe COPD exacerbations. In addition, using CPRD data did not allow for investigation of non-medical COPD treatments. Measures evaluated in the post-index observation period, such as MRC dyspnea scale score, were assessed at +1 day from index. Although this may have been shortly after initiation of new therapy, these measures are generally collected and recorded once a year during routine annual review and are likely to be distributed evenly through the year of follow-up. Persistence with the same treatment for the 12-month study duration without the need to step-up to additional therapies may indicate a healthier-than-average patient population, which could be a potential study limitation if applying these findings to a broader context. Estimates of treatment patterns following hospitalization may be underestimated, as medications prescribed to the patient while hospitalized may not be captured by the CPRD-GOLD database (as this information would need to be sent back to the GP from the hospital). Misclassification of drug exposure is a possible limitation because the CPRD-GOLD database provides information on prescribed, rather than dispensed, medications. In addition, prescription of a medication does not guarantee that a patient is fully compliant with the treatment regimen, which may impact treatment outcomes. Although this limitation is common to all maintenance treatment arms in the analysis, patients using multiple devices are likely to be less adherent to therapy than those using a single device. Finally, patients were required to have data captured in the database 12 months prior to, and after, the index date. As a result, data from patients who died before contributing 12 months of follow-up would not have been included in the analysis. Patients most likely to have been excluded due to this design constraint would have been those with more severe COPD and/or more comorbidities and would likely have had poorer outcomes. This may have resulted in an underestimation of the burden of COPD in these patients.

\section{Conclusions}

A large proportion of patients with COPD who were receiving monotherapy, dual therapies, or MITT continued to experience symptoms and exacerbations, despite persisting with the same treatment for 12 months or more and being seen by healthcare professionals. Our results suggest that many patients with COPD on mono or dual therapy who wish to escalate their treatment may be suitable for treatment modification according to GOLD COPD recommendations, to better control symptoms and reduce the risk of future exacerbations.

\section{Abbreviations}

BMI, body mass index; CI, confidence interval; COPD, chronic obstructive pulmonary disease; CPRD-GOLD, Clinical Practice Research Database - GP OnLine Data; $\mathrm{FEV}_{1}$, forced expiratory volume in 1 second; FF, fluticasone furoate; FVC, forced vital capacity; GOLD, Global Initiative for Chronic Obstructive Lung Disease; GP, general practitioner; HES, Hospital Episode Statistics; HES-APC, Hospital Episode Statistics Admitted Patient 
Care; HR, hazard ratio; ICD, International Classification of Diseases; ICS, inhaled corticosteroid; LABA, longacting $\beta_{2}$-agonist; LAMA, long-acting muscarinic antagonist; MITT, multiple-inhaler triple therapy; mMRC, (modified) Medical Research Council; NHS, National Health Service; NICE, National Institute for Health and Care Excellence; RR, rate ratio; SITT, single-inhaler triple therapy; TORCH, Towards a Revolution in COPD Health; UMEC, umeclidinium; VI, vilanterol.

\section{Data Sharing Statement}

The data analyzed in this publication are derived from the Clinical Practice Research Datalink (www.cprd.com) and Hospital Episode Statistics database (https://digital.nhs.uk/data-and-information/data-tools-and-services/data-services/hospitalepisode-statistics). Authors had access to the study data for the purposes of this work only. Data were accessed through an existing GSK license to address the prespecified research questions only. Therefore, the data cannot be broadly disclosed or made publicly available at this time. Access to each database can be requested via the respective websites.

\section{Ethics Approval and Informed Consent}

Approval of this study was provided by the GlaxoSmithKline Protocol Review Committee and by the Independent Scientific Advisory Committee (ISAC), which reviewed the protocol and approved access to Clinical Practice Research Datalink data (ISAC study no. 18_094). Patient consent was not required as anonymized patient-level data were used in this analysis.

\section{Acknowledgments}

Editorial support (in the form of writing assistance, including preparation of the draft manuscript under the direction and guidance of the authors, collating and incorporating authors' comments for each draft, assembling tables and figures, grammatical editing, and referencing) was provided by Fiona Goodwin, of Aura, a division of Spirit Medical Communications Group Limited (Manchester, UK), and was funded by GlaxoSmithKline. Trademarks are the property of their respective owners.

These data have previously been presented in abstract/poster form at the American Thoracic Society International Conference, Dallas, TX, USA, May 17-22, 2019: Sansbury L, Bains C, Ho S, Ismaila A, Anley G. Disease burden, health care utilization, and unmet need among chronic obstructive pulmonary disease (COPD) patients in United Kingdom (UK) general practice. D23. COPD: DIAGNOSIS AND EPIDEMIOLOGY. Am J Respir Crit Care Med. 2019; 199: A5944.

This study is based, in part, on data from the Clinical Practice Research Datalink obtained under license from the UK Medicines and Healthcare products Regulatory Agency. The data is provided by patients and collected by the NHS as part of their care and support. The interpretation and conclusions contained in this study are those of the authors alone.

Copyright (C) (2020), re-used with the permission of The Health \& Social Care Information Centre. All rights reserved.

\section{Author Contributions}

All authors made a significant contribution to the work reported, whether that was in the conception, study design, execution, acquisition of data, analysis and interpretation, or in all these areas; took part in drafting, revising, or critically reviewing the manuscript; gave final approval of the version to be published; have agreed on the journal to which the article has been submitted; and agree to be accountable for all aspects of the work.

\section{Funding}

This study was funded by GlaxoSmithKline (study number 208757/PRJ3187). The sponsor was involved in study conception and design, data interpretation, and the decision to submit the article for publication. The sponsor was also given the opportunity to review the manuscript for medical and scientific accuracy as well as intellectual property considerations. 


\section{Disclosure}

The authors declare the following conflicts of interest during the last three years in relation to this manuscript: DAL, GAA, KJR, and ASI are employees of and/or hold stocks/shares in GlaxoSmithKline. Current affiliation details for GAA and KJR: Speciality \& Primary Care, GlaxoSmithKline, Brentford, UK. LBS was an employee of and/or held stocks/ shares in GlaxoSmithKline at the time the study was conducted. LBS is currently affiliated with Global Epidemiology, Medical Affairs, Ultragenyx Pharmaceutical Inc., Novato, CA, USA. CB was a contingent worker at Value Evidence and Outcomes, R\&d Global Medical, GlaxoSmithKline, Uxbridge, UK, at the time of the study/analysis. ASI is also an unpaid part-time professor at McMaster University, Hamilton, ON, Canada. The authors report no other conflicts of interest in this work.

\section{References}

1. GOLD. Global initiative for Chronic Obstructive Pulmonary Disease (GOLD). 2021 Report; 2021. Available from: https://goldcopd.org/2021-goldreports/. Accessed February, 2021.

2. Rayner L, Sherlock J, Creagh-Brown B, Williams J, deLusignan S. The prevalence of COPD in England: an ontological approach to case detection in primary care. Respir Med. 2017;132:217-225. doi:10.1016/j.rmed.2017.10.024

3. British Lung Foundation. Chronic obstructive pulmonary disease (COPD) statistics; 2020. Available from: https://statistics.blf.org.uk/copd. Accessed July, 2020.

4. Schnell K, Weiss CO, Lee T, et al. The prevalence of clinically-relevant comorbid conditions in patients with physician-diagnosed COPD: a crosssectional study using data from NHANES 1999-2008. BMC Pulm Med. 2012;12:26. doi:10.1186/1471-2466-12-26

5. Murtagh E, O’Neill C, McAllister D, Kee F, Macmahon J, Heaney LG. A cross-sectional comparison of direct medical care costs among COPD and asthma patients living in the community in Northern Ireland. Treat Respir Med. 2006;5(6):495-501. doi:10.2165/00151829-200605060-00012

6. Punekar YS, Landis SH, Wurst K, Le H. Characteristics, disease burden and costs of COPD patients in the two years following initiation of long-acting bronchodilators in UK primary care. Respir Res. 2015;16:141. doi:10.1186/s12931-015-0295-2

7. NICE. NICE guideline - Chronic obstructive pulmonary disease in over 16s: diagnosis and management; 2018. Available from: https://www.nice. org.uk/guidance/ng115. Accessed January, 2021.

8. GOLD. Global initiative for Chronic Obstructive Pulmonary Disease (GOLD). 2017 Report; 2017. Available from: https://goldcopd.org/wp-content /uploads/2017/02/wms-GOLD-2017-FINAL.pdf. Accessed July, 2020.

9. Asche CV, Leader S, Plauschinat C, et al. Adherence to current guidelines for chronic obstructive pulmonary disease (COPD) among patients treated with combination of long-acting bronchodilators or inhaled corticosteroids. Int J Chron Obstruct Pulmon Dis. 2012;7:201-209. doi:10.2147/ COPD.S25805

10. Visentin E, Nieri D, Vagaggini B, Peruzzi E, Paggiaro P. An observation of prescription behaviors and adherence to guidelines in patients with COPD: real world data from October 2012 to September 2014. Curr Med Res Opin. 2016;32(9):1493-1502. doi:10.1080/ 03007995.2016.1182900

11. Sansbury LB, Bains C, Lipson DA, Ismaila AS, Landis SH. Real-world treatment patterns of multiple-inhaler triple therapy among patients with chronic obstructive pulmonary disease in UK general practice. Int J Chron Obstruct Pulmon Dis. 2021;16:1255-1264. doi:10.2147/COPD. S290773

12. MRC. Medical Research Council dyspnea scale; 1986. Available from: https://mrc.ukri.org/research/facilities-and-resources-for-researchers/mrcscales/mrc-dyspnoea-scale-mrc-breathlessness-scale/. Accessed January, 2021.

13. Rothnie KJ, Müllerová H, Thomas SL, et al. Recording of hospitalizations for acute exacerbations of COPD in UK electronic health care records. Clin Epidemiol. 2016;8:771-782. doi:10.2147/CLEP.S117867

14. Bogart M, Wu B, Germain G, et al. Real-world adherence to single-inhaler vs multiple-inhaler triple therapy among patients with COPD in a commercially insured US population. Chest. 2020;158(4):A1773-A1774. doi:10.1016/j.chest.2020.08.1548

15. Halpin D, Rothnie K, Banks V, et al. S27 Are patients with COPD more adherent to fluticasone furoate/umeclidinium/vilanterol (FF/UMEC/VI) compared with multiple-inhaler triple therapy in a real-world UK primary care treated population? Thorax. 2021;76(Suppl 2):A20-A21. Available from: https://horax.bmj.com/content/76/Suppl_2/A20.2. Accessed February 17, 2022.

16. Rothnie K, Czira A, Compton C, et al. Are patients with COPD more adherent to single-inhaler compared with multiple-inhaler triple therapy in a real-world UK primary care treated population? Eur Respir J. 2021;58:OA2947. doi: 0.1183/13993003.congress-2021.OA2947

17. Gloeckl R, Schneeberger T, Jarosch I, Kenn K. Pulmonary rehabilitation and exercise training in chronic obstructive pulmonary disease. Dtsch Arztebl Int. 2018;115:117-123. doi:10.3238/arztebl.2018.0117

18. Dalon F, Devouassoux G, Belhassen M, et al. Impact of therapy persistence on exacerbations and resource use in patients who initiated COPD therapy. Int J Chron Obstruct Pulmon Dis. 2019;14:2905-2915. doi:10.2147/COPD.S222762

19. Chrystyn H, Small M, Milligan G, Higgins V, Gil EG, Estruch J. Impact of patients' satisfaction with their inhalers on treatment compliance and health status in COPD. Respir Med. 2014;108(2):358-365. doi:10.1016/j.rmed.2013.09.021

20. Ismaila A, Corriveau D, Vaillancourt J, et al. Impact of adherence to treatment with tiotropium and fluticasone propionate/salmeterol in chronic obstructive pulmonary diseases patients. Curr Med Res Opin. 2014;30(7):1427-1436. doi:10.1185/03007995.2014.908828

21. Toy EL, Beaulieu NU, McHale JM, et al. Treatment of COPD: relationships between daily dosing frequency, adherence, resource use, and costs. Respir Med. 2011;105(3):435-441. doi:10.1016/j.rmed.2010.09.006

22. Vestbo J, Anderson JA, Calverley PMA, et al. Adherence to inhaled therapy, mortality and hospital admission in COPD. Thorax. $2009 ; 64(11): 939$. doi:10.1136/thx.2009.113662

23. Covvey JR, Mullen AB, Ryan M, et al. A comparison of medication adherence/persistence for asthma and chronic obstructive pulmonary disease in the United Kingdom. Int J Clin Pract. 2014;68(10):1200-1208. doi:10.1111/ijcp.12451 
24. Mueller S, Wilke T, Bechtel B, Punekar YS, Mitzner K, Virchow JC. Non-persistence and non-adherence to long-acting COPD medication therapy: a retrospective cohort study based on a large German claims dataset. Respir Med. 2017;122:1-11. doi:10.1016/j.rmed.2016.11.008

25. Wurst KE, St Laurent S, Mullerova H, Davis KJ. Characteristics of patients with COPD newly prescribed a long-acting bronchodilator: a retrospective cohort study. Int J Chron Obstruct Pulmon Dis. 2014;9:1021-1031. doi:10.2147/COPD.S58258

26. Bogart M, Stanford RH, Laliberté F, Germain G, Wu JW, Duh MS. Medication adherence and persistence in chronic obstructive pulmonary disease patients receiving triple therapy in a USA commercially insured population. Int J Chron Obstruct Pulmon Dis. 2019;14:343-352. doi:10.2147/ COPD.S184653

27. European Medicines Agency. Trelegy Ellipta Summary of product characteristics; 2019. Available from: https://www.ema.europa.eu/en/documents/ product-information/trelegy-ellipta-epar-product-information_en.pdf. Accessed July, 2020.

28. European Medicines Agency. Trimbow - Summary of product characteristics; 2017. Available from: https://www.ema.europa.eu/en/documents/ product-information/trimbow-epar-product-information_en.pdf. Accessed July, 2020.

29. European Medicines Agency. Trixeo aerosphere - Summary of product characteristics; 2020. Available from: https://www.ema.europa.eu/en/ documents/product-information/trixeo-aerosphere-epar-product-information_en.pdf. Accessed January, 2021.

30. Lai CC, Chen CH, Lin CYH, Wang CY, Wang YH. The effects of single inhaler triple therapy vs single inhaler dual therapy or separate triple therapy for the management of chronic obstructive pulmonary disease: a systematic review and meta-analysis of randomized controlled trials. Int J Chron Obstruct Pulmon Dis. 2019;14:1539-1548. doi:10.2147/COPD.S200846

31. Langham S, Lewis J, Pooley N, et al. Single-inhaler triple therapy in patients with chronic obstructive pulmonary disease: a systematic review. Respir Res. 2019;20(1):242. doi:10.1186/s12931-019-1213-9

32. Lipson DA, Barnacle H, Birk R, et al. FULFIL trial: once-daily triple therapy for patients with chronic obstructive pulmonary disease. Am J Respir Crit Care Med. 2017;196(4):438-446. doi:10.1164/rccm.201703-0449OC

33. Lipson DA, Barnhart F, Brealey N, et al. Once-daily single-inhaler triple versus dual therapy in patients with COPD. $N$ Engl J Med. 2018 ;378 (18):1671-1680. doi:10.1056/NEJMoa1713901

34. Lipson DA, Crim C, Criner GJ, et al. Reduction in all-cause mortality with fluticasone furoate/umeclidinium/vilanterol in patients with chronic obstructive pulmonary disease. Am J Respir Crit Care Med. 2020;201(12):1508-1516. doi:10.1164/rccm.201911-2207OC

35. Tabberer M, Lomas DA, Birk R, et al. Once-daily triple therapy in patients with COPD: patient-reported symptoms and quality of life. Adv Ther. 2018;35(1):56-71. doi:10.1007/s12325-017-0650-4

36. Singh D, Papi A, Corradi M, et al. Single inhaler triple therapy versus inhaled corticosteroid plus long-acting $\beta 2$-agonist therapy for chronic obstructive pulmonary disease (TRILOGY): a double-blind, parallel group, randomised controlled trial. Lancet. 2016;388(10048):963-973. doi:10.1016/S0140-6736(16)31354-X

37. Rabe KF, Watz H. Chronic obstructive pulmonary disease. Lancet. 2017;389(10082):1931-1940. doi:10.1016/S0140-6736(17)31222-9

38. Halpin DMG, Worsley S, Ismaila AS, et al. INTREPID: single- versus multiple-inhaler triple therapy for COPD in usual clinical practice. ERJ Open Res. 2021;7:00950-02020. doi:10.1183/23120541.00950-2020

39. Yu AP, Guérin A, Ponce de Leon D, et al. Therapy persistence and adherence in patients with chronic obstructive pulmonary disease: multiple versus single long-acting maintenance inhalers. J Med Econ. 2011;14(4):486-496. doi:10.3111/13696998.2011.594123

40. Romagnoli A, Santoleri F, Costantin A. Adherence and persistence analysis after three years in real-life of inhalation therapies used in the treatment of COPD. Curr Med Res Opin. 2020;36(12):2055-2061. doi:10.1080/03007995.2020.1841617

41. Miravitlles M, Marín A, Huerta A, Carcedo D, Villacampa A, Puig-Junoy J. Estimation of the clinical and economic impact of an improvement in adherence based on the use of once-daily single-inhaler triple therapy in patients with COPD. Int J Chron Obstruct Pulmon Dis. 2020;15:643-1654. doi: $10.2147 /$ COPD.S253567

42. Herrett E, Gallagher AM, Bhaskaran K, et al. Data resource profile: Clinical Practice Research Datalink (CPRD). Int J Epidemiol. 2015;44 (3):827-836. doi:10.1093/ije/dyv098

International Journal of Chronic Obstructive Pulmonary Disease

\section{Publish your work in this journal}

The International Journal of COPD is an international, peer-reviewed journal of therapeutics and pharmacology focusing on concise rapid reporting of clinical studies and reviews in COPD. Special focus is given to the pathophysiological processes underlying the disease, intervention programs, patient focused education, and self management protocols. This journal is indexed on PubMed Central, MedLine and CAS. The manuscript management system is completely online and includes a very quick and fair peer-review system, which is all easy to use. Visit http://www. dovepress.com/testimonials.php to read real quotes from published authors.

Submit your manuscript here: https://www.dovepress.com/international-journal-of-chronic-obstructive-pulmonary-disease-journal 